$\begin{array}{cc}\text { ACADEMIA ROMÂNĂ } & \text { Rev. Roum. Chim., } \\ \text { Revi, 66(1), 87-93 } & \text { Revue Roumaine de Chimie } \\ \text { http://web.icf.ro/rrch/ } & \text { DOI: 10.33224/rrch.2021.66.1.10 }\end{array}$

Dedicated to Professor Mihaela Hillebrand, on the occasion of her $80^{\text {th }}$ anniversary

\title{
PREPARATION AND SURFACE CHARACTERIZATION OF POLYURETHANE HYDROGELS
}

\author{
Mihaela BARBALATA-MANDRU, ${ }^{*}$ Maria BERCEA, Luiza Madalina GRADINARU, \\ Magdalena AFLORI and Radu ALBULESCU \\ "Petru Poni" Institute of Macromolecular Chemistry, 41-A Grigore Ghica Voda Alley, 700487, Iaşi, Roumania \\ ${ }^{a}$ Polymer Adhesive Tapes SRL, 96-B Timisoara Boulevard, 6th District, Bucharest, Roumania
}

In the present study, new hydrogels based on polyurethane (PU) and poly(vinyl alcohol) PVA were obtained by freezing-thawing method from aqueous solution. The surfaces of PU/PVA hydrogels were characterized in terms of porosity, roughness, water swelling, Raman and Attenuated Total Reflection Fourier Transform Infrared (ATR-FTIR) spectroscopy. The average pore size increased from $0.6 \mu \mathrm{m}$ to $21 \mu \mathrm{m}$ for pure PVA and the PU/PVA hydrogels. The Raman and ATR-FTIR analysis provided hydrophobic interactions and hydrogen bonds interactions between the hydroxyl groups from PVA with the large number of urethane groups from polyurethane. The
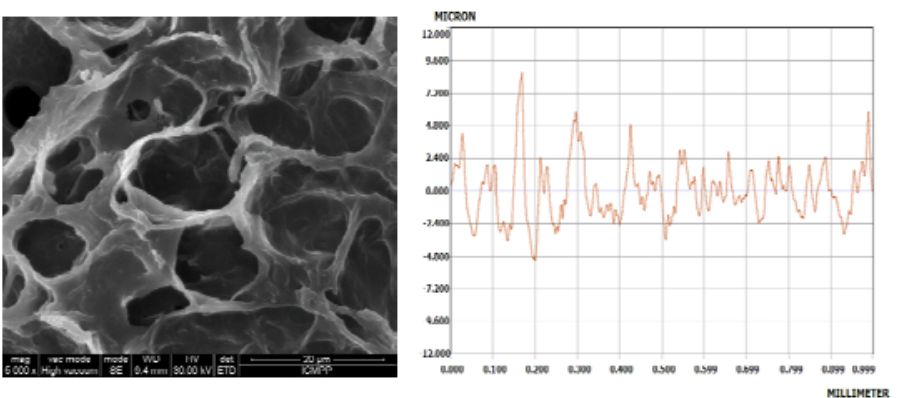
incorporation of polyurethane also increased the surface roughness and the swelling water of the PVA hydrogels and made the surface more porous, a desirable feature for biomedical application.

\section{INTRODUCTION}

Hydrogels based on polymer mixture is a suitable method of making materials with desired surface properties. This is a simple method which combines the advantages of different versatile and promising polymeric materials with potential applications in various domains. ${ }^{1}$ The resulting networks may show a synergistic behavior ${ }^{1,2}$ and a stable surface with controlling properties. ${ }^{3}$ Whatever their biomedical application will be, due to their flexibility, high water content, soft consistency, porosity they nearly simulate the natural living tissue. ${ }^{2,4}$
An interesting category of hydrogels are represented by thermoreversible polyurethanes due to the versatility of the components used in their preparation. ${ }^{5-8}$ The properties are strongly influenced by the hydrophilic and hydrophobic blocks used in the structure and the composition of their hard and soft segments. They can offer water solubility (especially at low temperature) and the possibility to display different interactions such as hydrophobic and hydrogen bonds. ${ }^{7}$ Blending of thermoreversible polyurethane hydrogels with various polymer materials is one of the suitable and efficient ways for improving his properties and his potential applications such as membranes for wound dressing. ${ }^{9}$

${ }^{1}$ Corresponding author: mandru.mihaela@icmpp.ro 
On the other hand, poly(vinyl alcohol) (PVA) is a water-soluble, biodegradable, non-toxic, biocompatible synthetic polymer used as physical crosslinked hydrogels. ${ }^{10-12}$ The hydroxyl groups, presented in each repeating unit, confer a hydrophilic character of surface and hydrogen bonding ability. Due to its capacity to form chemical or physical crosslinked networks the PVA hydrogels prepared by repeated cycles of freezing/thawing is used in combination with other biocompatible polymers. ${ }^{9,13}$ The present work, investigates the surface properties of a new PU/PVA hydrogels such as porosity, roughness water swelling or intermolecular interactions, which play an important role in the development of biomaterials.

\section{RESULTS AND DISCUSSION}

\section{ATR-FTIR and RAMAN analysis}

ATR-FTIR absorption spectra for pure PVA and PU/PVA hydrogels are related in Figure 1. The purpose of the ATR-FTIR analysis was to characterize the prepared hydrogels, to obtain some information on the formation of the PU/PVA hydrogel structures and to evidence their interactions. Thereby, the ATR spectra of pure PVA and PU/PVA hydrogel reveals the characteristic absorption peaks in the regions: 3500-3329 $\mathrm{cm}^{-1} \quad v(\mathrm{O}-\mathrm{H}$ stretching $), \quad v(\mathrm{~N}-\mathrm{H}$ stretching), $2940-2907 \mathrm{~cm}^{-1} v(\mathrm{C}-\mathrm{H}$ stretching $)$ of -
$\mathrm{CH}_{2}$ and $-\mathrm{CH}_{3}$ groups, $1651 \mathrm{~cm}^{-1}$ (the residual acetate peak $), 1418-1236 \mathrm{~cm}^{-1} \delta(\mathrm{C}-\mathrm{H}$ bending $)$, $1142-1089 \mathrm{~cm}^{-1} v(\mathrm{C}-\mathrm{O}-\mathrm{C}$ stretching $)$ of ether group (Fig. 1). ${ }^{9,12,14-15}$

The presence of the hydrogen bonding interactions between amide groups of PU and hydroxyl groups of the PVA are well highlighted by the spectral changes, especially in the region 3400$3320 \mathrm{~cm}^{-1}$ and $1703-1599 \mathrm{~cm}^{-1}$ and the hydrophobic interactions involving the methylene or propylene oxide groups are presented in the region 2940-2907 $\mathrm{cm}^{-1}$ and $1400-1300 \mathrm{~cm}^{-1}$ (Fig. 1).

The band from the region $3400-3320 \mathrm{~cm}^{-1}$ typical for $-\mathrm{OH}$ band increased in intensity with the polyurethane incorporation.

The band from $2940-2907 \mathrm{~cm}^{-1}$ region (typical for asymmetrical and symmetrical $\mathrm{C}-\mathrm{H}$ bond) appears in the spectra of PVA and PU/PVA hydrogels and rises in intensity as the PU content increases.

The bands of 1736 and $1655 \mathrm{~cm}^{-1}$ (free and bonded $\mathrm{C}=\mathrm{O}$ stretching of urethane and PVA) visible in the spectra of pure PVA and PU/PVA hydrogels are more obvious at the highest concentration of PU.

Moreover, the peaks from the region 1400 $1300 \mathrm{~cm}^{-1}$, typically for $-\mathrm{CH}_{2}$ and $-\mathrm{CH}_{3}$ asymmetrical and symmetrical deformation vibration and to the bending vibration $\delta(\mathrm{CH}-\mathrm{OH})$ from pure PVA becomes wider and shifts to different wavenumbers indicating the presence of the interactions between the components (Fig. 1). ${ }^{12,16}$

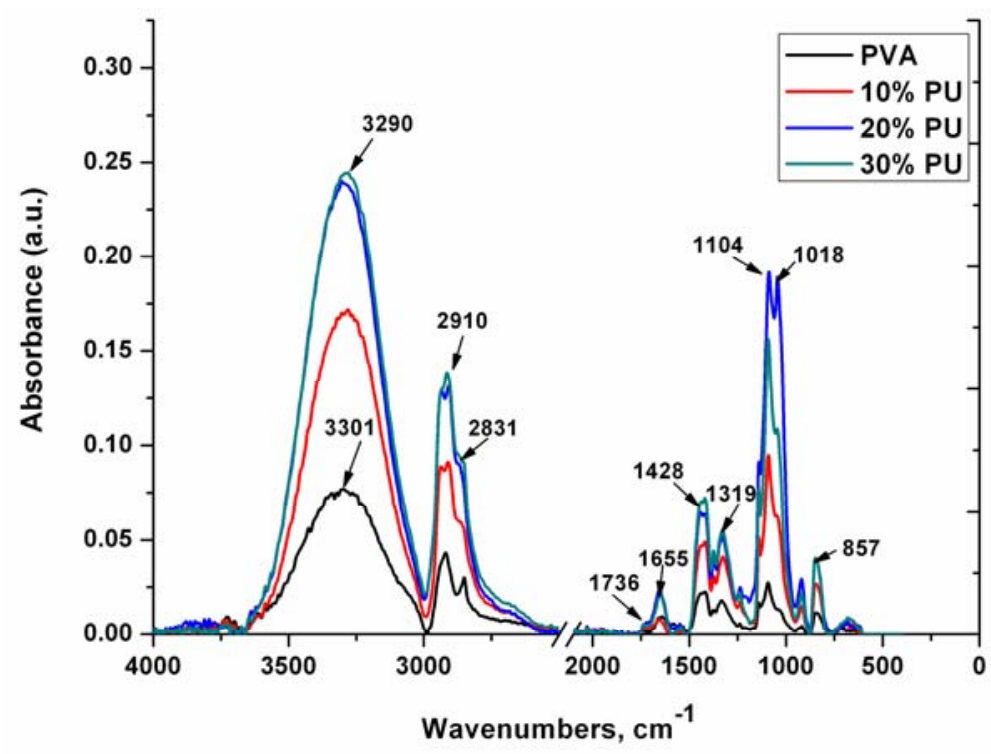

Fig. 1 - ATR-FTIR spectra of pure PVA and PU/PVA dried samples. 


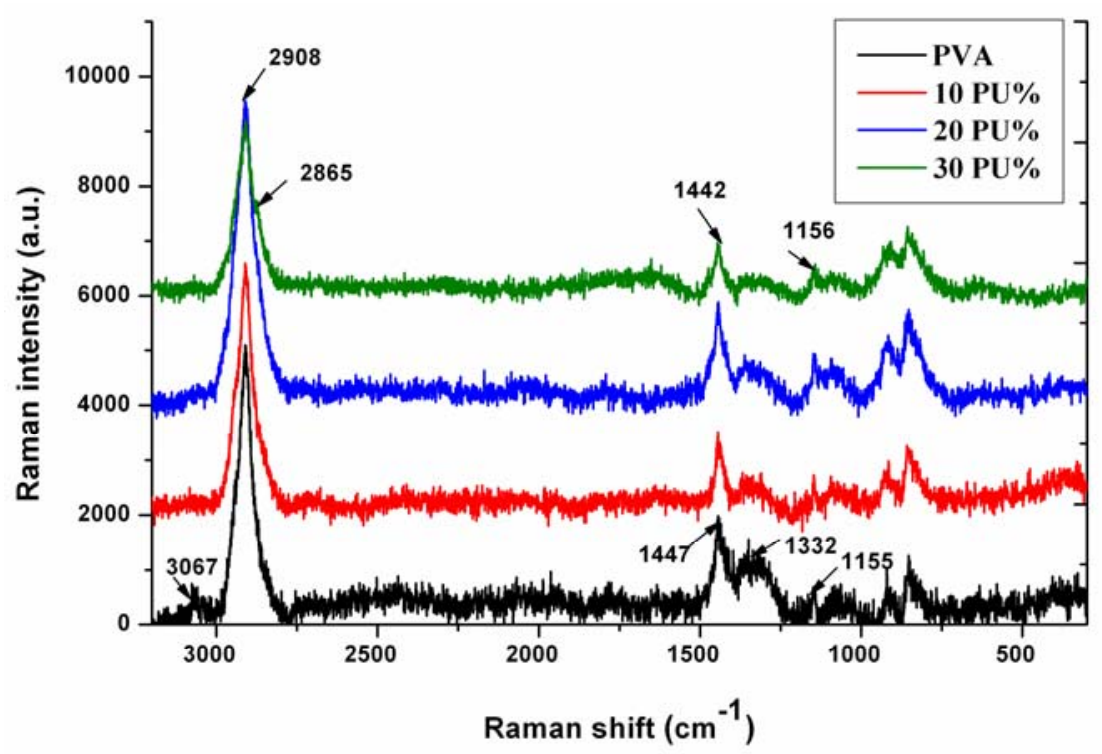

Fig. 2 - Raman spectra of pure PVA and PU/PVA dried samples.

Another complementary technique to infrared spectroscopy is represented by Raman spectroscopy, which also measures the nature of chemical bonds, interactions or conformations. Fig. 2 presents the Raman spectra of the samples, containing several distinct bands. The spectral changes confirm the formation of some interactions in the region 2940$2907 \mathrm{~cm}^{-1}$ through the presence of the characteristic band of asymmetric stretching vibrations $v\left(\mathrm{CH}_{2}\right)$ asim at $2908 \mathrm{~cm}^{-1}$ and symmetric stretching vibrations $v\left(\mathrm{CH}_{2}\right)_{\text {sim }}$ at $2865 \mathrm{~cm}^{-1}$ respectively, and in the region $1400-1300 \mathrm{~cm}^{-1}$ through the deformation vibration band $\delta(\mathrm{C}-\mathrm{H})$ at $1442 \mathrm{~cm}^{-1}$ of $\mathrm{CH}_{3}$ group. ${ }^{17-}$ 18 Also, the presence of hydrogen bonding interactions are highlighted especially in the region $1150-1104 \mathrm{~cm}^{-1}$ at $1156 \mathrm{~cm}^{-1}$ where the stretching vibration of the $v(\mathrm{C}-\mathrm{O})$ group in the aliphatic ether was found. ${ }^{17}$

The obtained spectra confirmed the incorporation of the PU in the PU/PVA hydrogels and also the formations of different inter and intra molecular interactions.

\section{SEM analysis}

The investigation of SEM images can relate valuable information about material's morphology. The selected hydrogel prepared from PVA and the thermoreversible PU, shows a porous structure with interconnected and irregular pores and a size ranging from $0.6 \mu \mathrm{m}$ to $21 \mu \mathrm{m}$ (Fig. 3). Furthermore, the expansion of pores increased in the PU/PVA hydrogels after the adding of PU, due to the different interactions (hydrophobic interactions and hydrogen bonding) established between the polymers which influence their morphology. ${ }^{2}$ The applying of several freezing/ thawing cycles changes the supramolecular structure and formed a porous network at room temperature during the thawing. ${ }^{19}$ The hydrogel obtained from the sample with the highest PU concentration $(30 \% \mathrm{PU})$ is characterized by a porous structure, with a diameter of pores randomly distributed up to $21 \mu \mathrm{m}$ (Fig. 4). The polymer composition and the freezing/thawing process, reveal an important role in the formation of pores shape and size in order to permit the grow of cells, feature which is desirable in applications like drug delivery, tissue engineering. Nevertheless, the results verify the further results as the swelling behavior.

\section{Surface roughness}

The roughness parameters measured with the profiler revealed an increase in the surface roughness by addition of PU into the PVA hydrogels. The obtained value of the roughness, $R_{a}$ are from $0.774 \mu \mathrm{m}$ (PVA), $0.914 \mu \mathrm{m}(10 \% \mathrm{PU})$, $0.984 \mu \mathrm{m}(20 \% \mathrm{PU})$ and $1.110 \mu \mathrm{m}(30 \% \mathrm{PU})$ and followed the order, PVA $<10 \% \mathrm{PU}<20 \%$ PU $<$ $30 \%$ PU. The highest roughness of $1.110 \mu \mathrm{m}$ was obtained for the 30\% PU hydrogel (Fig. 5). An increase in the pore size of the samples gives an enhanced roughness as it is listed in the profilometer images. This can be explained by the SEM images where the incorporation of PU in the hydrogels increases the size of the pores (Fig. 4). The results are consistent with another study reported in the literature for polyacrylonitrile/ polyurethane $(\mathrm{PAN}) /(\mathrm{PU}) .^{20}$ 


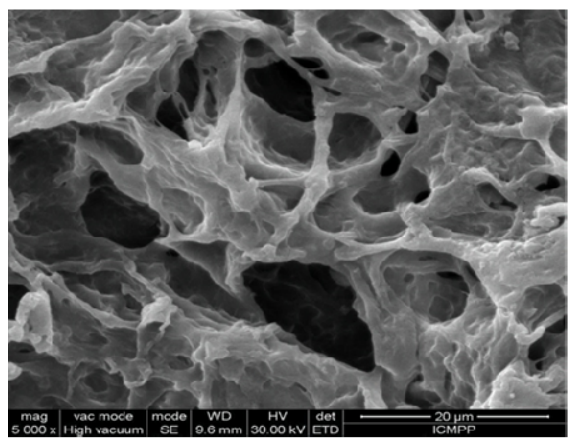

a)

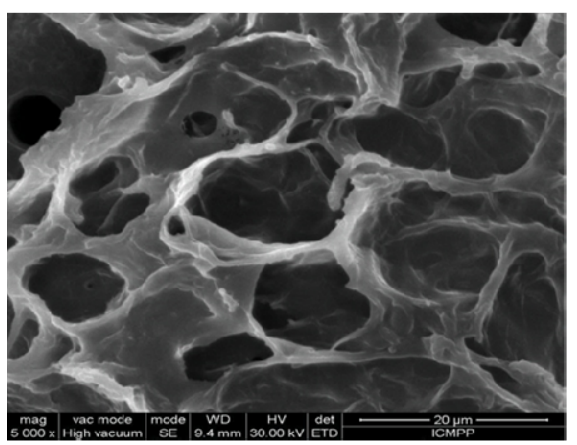

c)

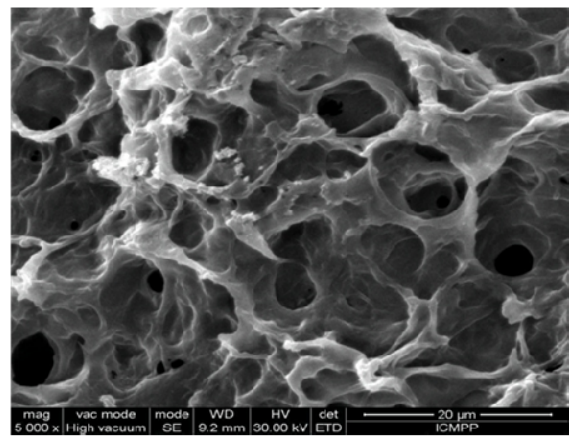

b)

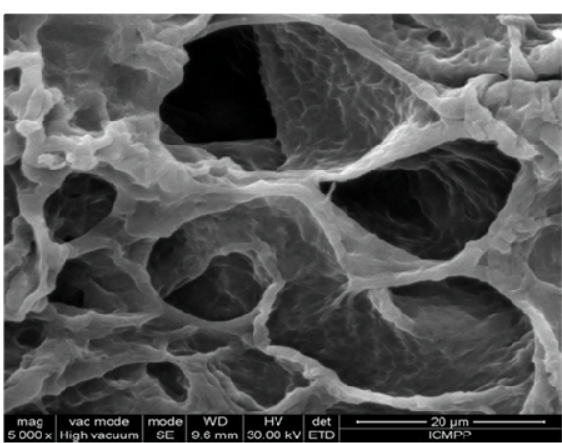

d)

Fig. 3 - SEM microphotographs ( $\times 500$ magnification) of (a) PVA, (b) $10 \%$ PU, (c) $20 \% \mathrm{PU}$ (d) $30 \%$ PU.

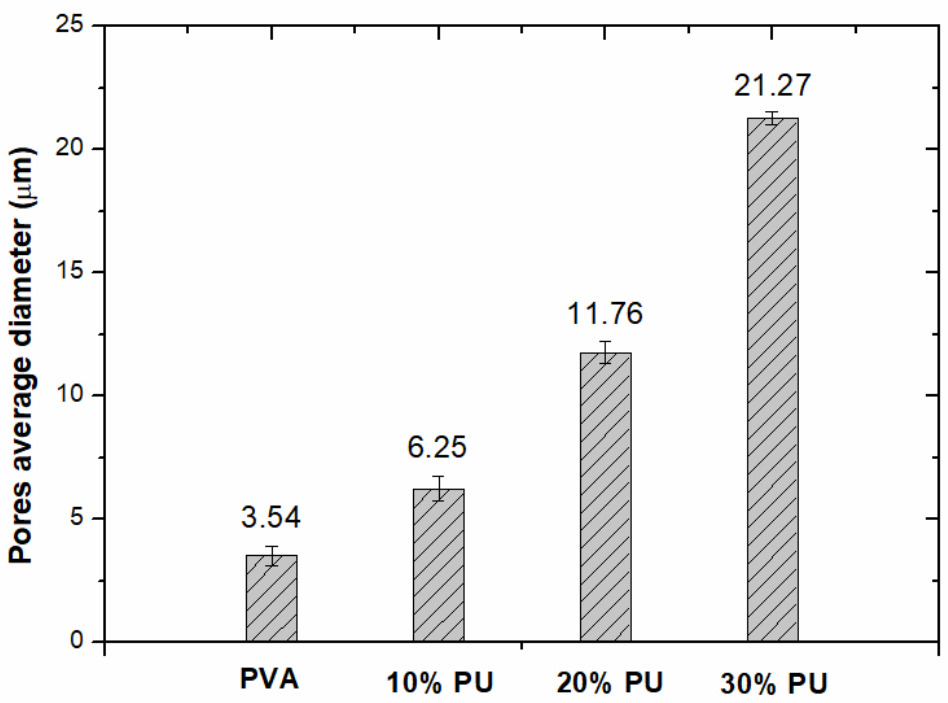

Fig. 4 - Pores average diameter as a function of PU content.

\section{SWELLING EXPERIMENTS}

The swelling behavior of hydrogels is important in biomedical applications because this feature can establish a moist environment for curing different types of wounds, can be usefully for absorbing wound exudates or can influence the release of bioactive substances from the hydrogels matrix. The swelling behaviors of PU/PVA hydrogel with different polyurethane content was measured in Millipore water at $37^{0} \mathrm{C}$ and it is described in
Fig.6. The presence of some groups like hydroxyl and carbonyl in the PU/PVA hydrogels give them a hydrophilic character. The swelling reached the equilibrium at about $288 \%$ for the higher concentration $30 \% \mathrm{PU} / \mathrm{PVA}$ and is characterized by three steps of water swelling: a rapid, a slow and an equilibrium phase. The rapid increase occurs in the first $10 \mathrm{~min}$ and the equilibrium plateau is achieved after about $110 \mathrm{~min}$ for PU/PVA hydrogels. However, the PVA sample 
reached the equilibrium in less than $100 \mathrm{~min}$. The presence of polyurethane structure in the hydrogels decreases the ability of the PVA to form $-\mathrm{OH}$ bonds with other PVA chains thus causing an increase in water swelling for PU/PVA hydrogels. The swelling behavior depends on structure, morphology and dimensions of pores and the results reported here are in good agreement with data reported in the literature. ${ }^{2,9}$ Thus, the amount of polyurethane introduced into the PVA network influenced the penetration of water into the obtained hydrogels, resulting in an improvement of the hydrogels properties. The affinity of hydrogels for water is an important feature in conferring the ability to simulate the natural tissue.

Obviously, the gel fraction increased with the incorporation of different concentrations of $\mathrm{PU}$ in the following order: $\mathrm{PVA}<10 \% \mathrm{PU}<20 \% \mathrm{PU}<$ $30 \% \mathrm{PU}, 85 \%, 87 \%, 88 \%, 90 \%$, respectively. This feature may be attributed to the presence of different inter- and intramolecular interactions between PVA and PU, confirmed by ATR-FTIR and RAMAN analysis. From the present data, it can be assumed that a more stable structure is obtained by the physical interactions between the two polymers. Small fractions of PU and PVA chains that were not incorporated into the overall network structure of PU/PVA hydrogels were dissolved into water.

\section{EXPERIMENTAL}

\section{Materials}

Poly(vinyl alcohol) (PVA) with molecular weight $M_{w}=$ $1.3 \times 10^{5} \mathrm{~g} / \mathrm{mol}(99 \%$ hydrolized) was acquired from SigmaAldrich. PU was prepared according to an experimental procedure previously reported ${ }^{2,21}$ by using poly(ethylene oxide)-poly(propylene oxide)-poly(ethylene oxide) triblock copolymer (B) with $\mathrm{M}_{\mathrm{n}}=5800 \mathrm{Da}$ as soft segments, isopropyl ricinoleate diol (A) with $M_{n}=358 \mathrm{Da}$ and 1,6-hexamethylene diisocyanate as hard segment and a bifunctional derivative of phosphatidylcholine (C) with $\mathrm{M}_{\mathrm{n}}=592 \mathrm{Da}$ as chain extender. $\mathrm{A}$ and $\mathrm{C}$ were synthesized in our laboratory, $\mathrm{B}$ and the aliphatic diisocyanate were purchased from Sigma-Aldrich (Germany). The PU and PVA structures are shown in Scheme 1 .

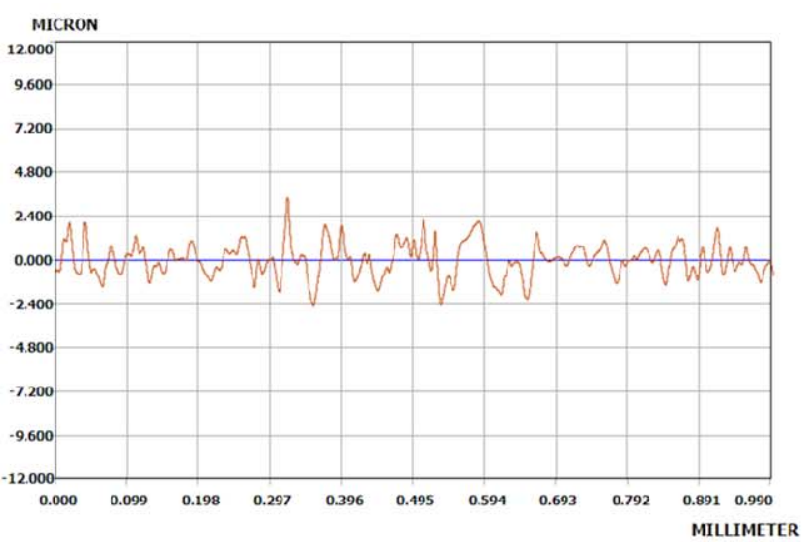

a)

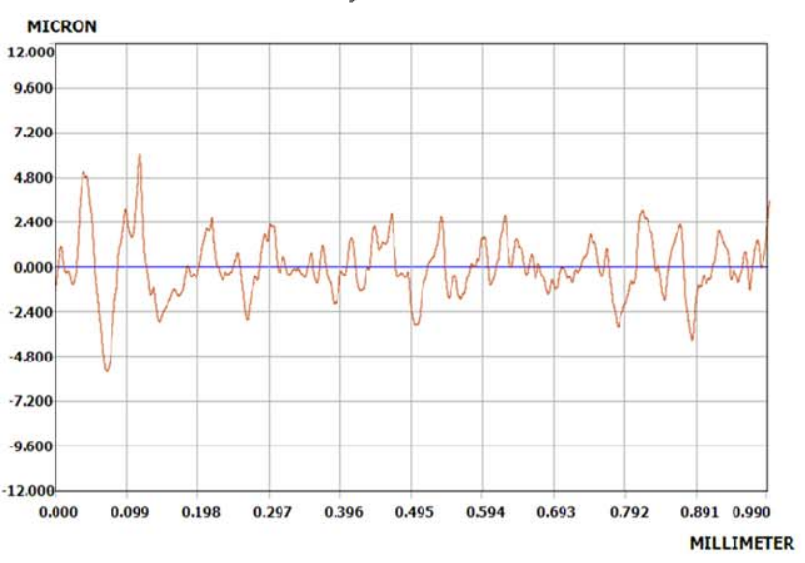

c)

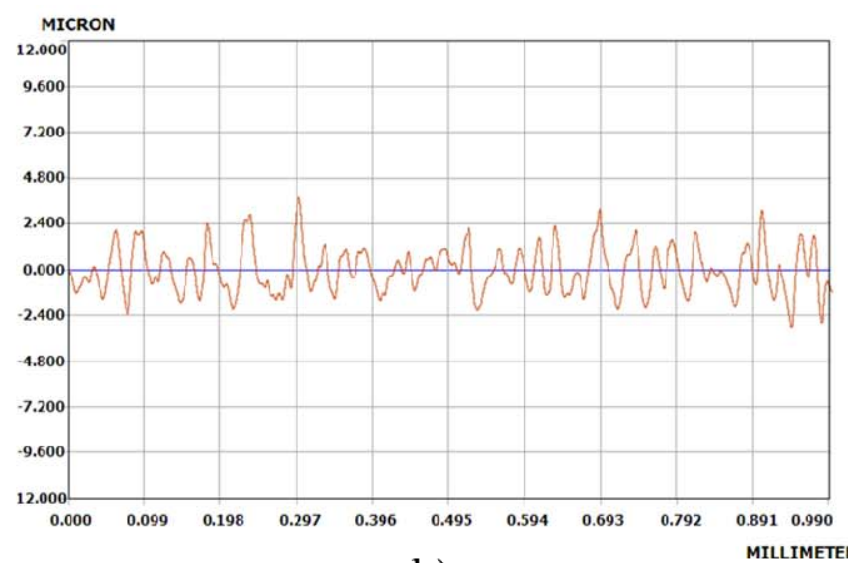

b)

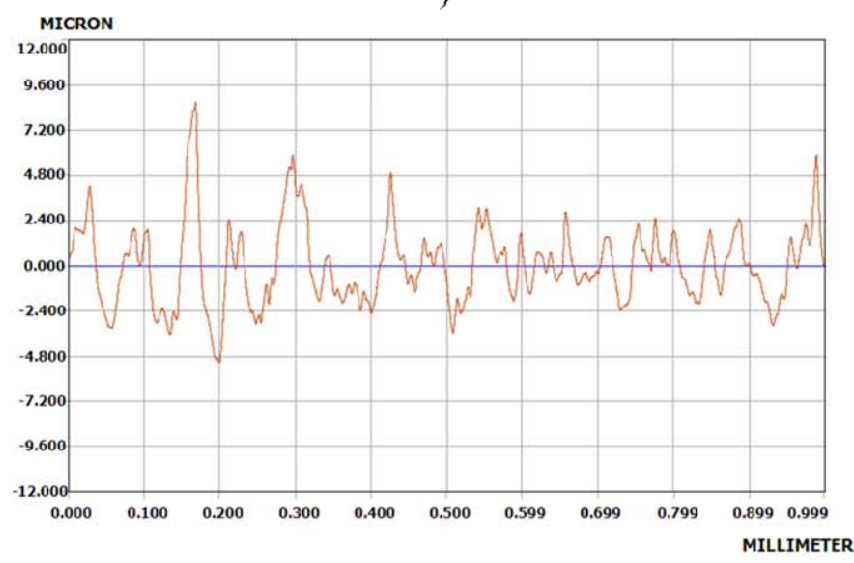

d)

Fig. 5 - Profiler roughness measurements of samples (a) PVA, (b) $10 \% \mathrm{PU}$, (c) $20 \% \mathrm{PU}$ (d) $30 \% \mathrm{PU}$. 


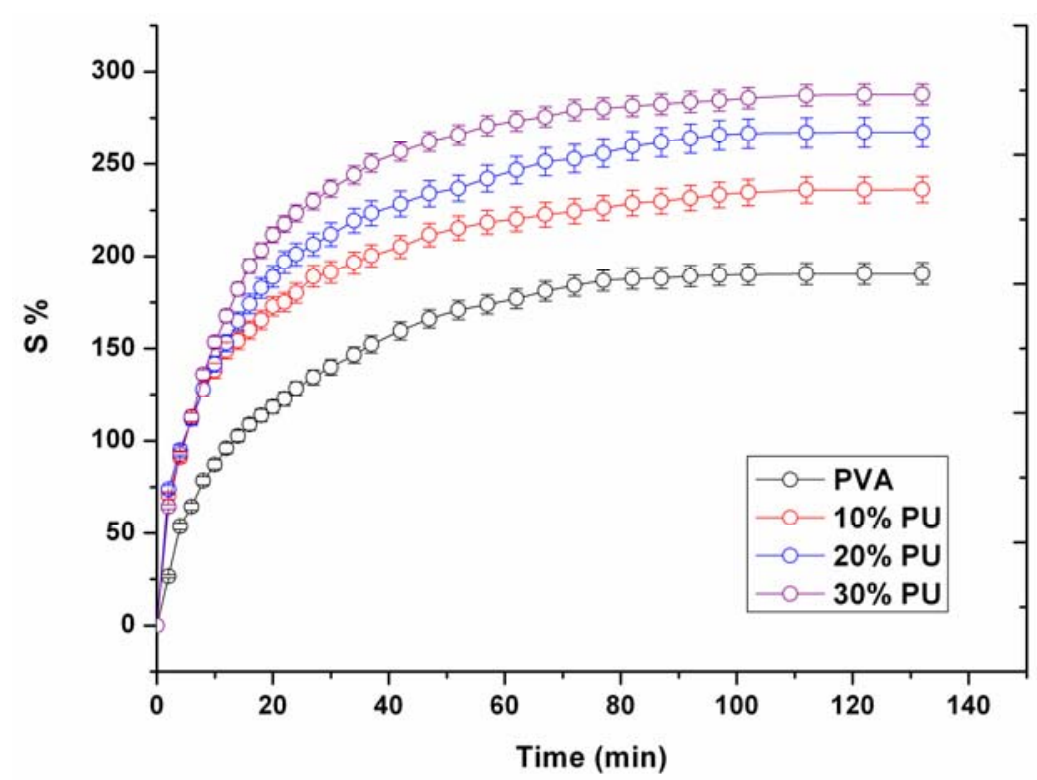

Fig. 6 - Swelling behaviors of PVA and PU/PVA hydrogels.

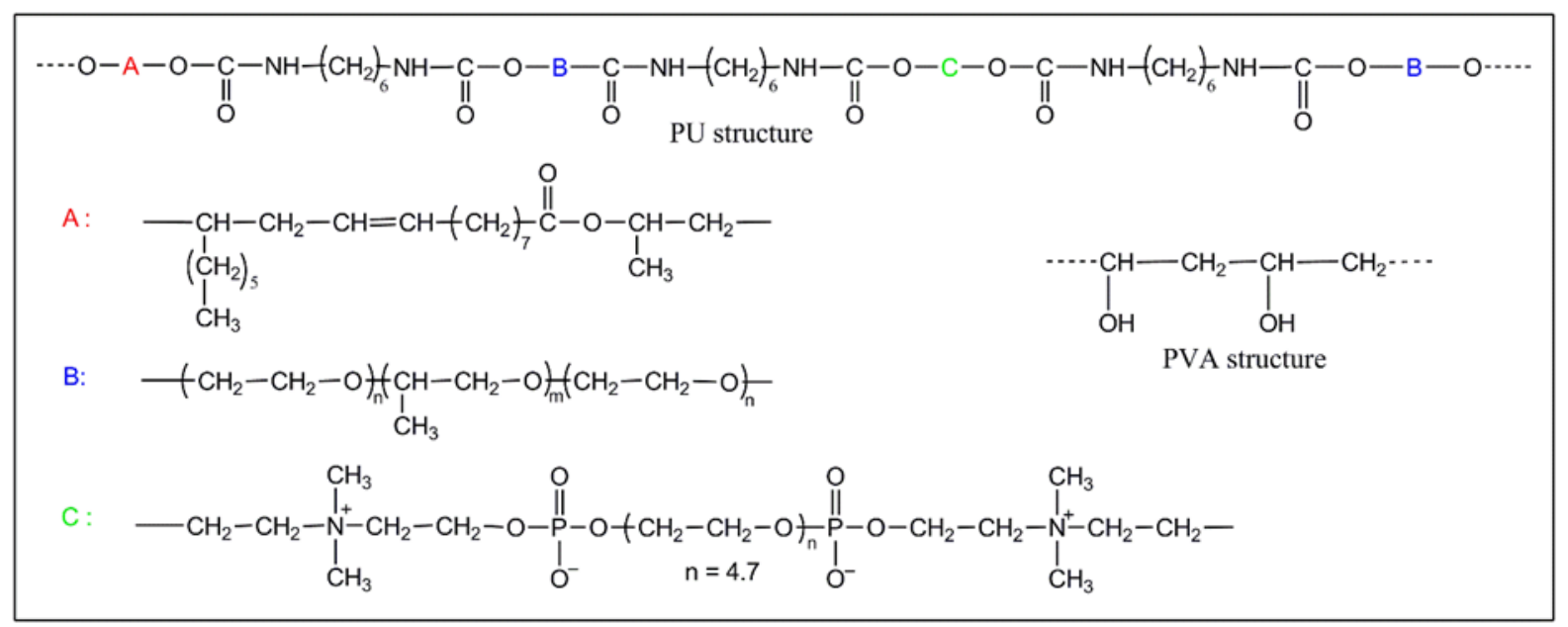

Scheme 1 - Polyurethane and poly(vinyl alcohol) structure.

The physical characteristics of the PU were: $M_{n}=19 \mathrm{KDa}$; Critical micelle concentration $=0.6 \times 10^{-6} \mathrm{~mol} / \mathrm{l}$; Gelation temperature $=28{ }^{\circ} \mathrm{C}$ and Time of gelation at $37^{\circ} \mathrm{C}=60 \mathrm{sec}$ (based on rheological measurements).

\section{Preparation of the samples}

Homogeneous PU and PVA aqueous solutions of $8 \%$ (wt.\%) were used to prepare mixtures of PU/PVA with different content of PU (expressed as weight percent, $w_{\mathrm{PU}}$ ): $10 \%, 20 \%, 30 \%$. PU solution was prepared by mixing the polymer with Millipore water under mechanical stirring until the complete dissolution. The solution was kept $24 \mathrm{~h}$ at $4{ }^{\circ} \mathrm{C}$ for homogenization. PVA was dissolved under magnetic stirring in Millipore water at $80{ }^{\circ} \mathrm{C}$ for a period of $2 \mathrm{~h}$. The solution was kept overnight at room temperature. Then, according to a previously procedure related for PVA based hydrogels $\mathrm{s}^{22}$, some porous hydrogels were obtained after submitting the solutions to 3 consecutive freezing/thawing cycles $\left(16 \mathrm{~h}\right.$ freezing step at $-20^{\circ} \mathrm{C}, 8 \mathrm{~h}$ thawing step up to $37^{\circ} \mathrm{C}$ ). The resulted hydrogels were lyophilized by an Alpha 1-2 LD Martin Christ instrument and their characteristics were investigated.

\section{Characterization methods}

The infrared spectra were registered on a Bruker LUMOS FT-IR Microscope using the ATR reflection module (Attenuated Total Reflection) equipped with a diamond crystal and provided with software for spectral processing. The hydrogels surface was scanned in the range $600-4000 \mathrm{~cm}^{-1}$, at a $45^{\circ}$ angle. The ATR-FTIR spectra were recorded at a constant temperature of $25^{\circ} \mathrm{C}$.

The Raman spectra of the samples were recorded using a confocal Raman microscope spectrometer (Renishaw plc, Gloucestershire, UK) inVia, equipped with a Leica DM2700 microscope with $5 x, 20 x$ and $100 x$ objectives and a Renishaw CCD Centrus detector. The samples were measured directly from the metal disks.

The hydrogel morphology of the surfaces was observed using an environmental scanning electron microscope (ESEM), working at $5 \mathrm{kV}$ with secondary electrons in high vacuum mode. The samples were mounted on graphite supports and analysed under different degrees of magnifications. The surface images were taken from the most relevant aspects and the pores diameters were measured using 
ImageJ software. The maximum pores average diameters with the obtained values were made using the OriginPro8 software.

The roughness parameter of all samples was measured with a computerized and high sensitivity Tencor Alpha-Step D-500 stylus profiler (KLA Tencor Corporation, Milpitas, CA, USA) by a recording speed of $0.10 \mathrm{~mm} / \mathrm{s}$. This device measures the height of the steps with an accuracy ranging between $10 \AA$ and $1.2 \mathrm{~mm}$ and a loading force of $15 \mathrm{mg}$. The average square roughness $(\mathrm{Ra})$ of the surface measured by the profilometer reaches a filtration interval of $0.060 \mathrm{~mm}$ and was tested in triplicate.

The swelling degree of hydrogels was measured in Millipore water at $37^{\circ} \mathrm{C}$. The sample disks in lyophilized state with a diameter of $10 \mathrm{~mm}$ were weighted and immersed in $5 \mathrm{ml}$ of Millipore water in a closed bottle. These bottles were placed in a thermostatic bath at $37^{\circ} \mathrm{C}$. At each time interval, the samples were removed from the bottle, the swollen hydrogel surface was wiped off by using an absorbent paper and the excess water was removed before the accurately weighing. The measurements were made in triplicate. The swelling degree (\%) was calculated by the equation:

$$
S \%=\frac{W_{t}-W_{0}}{W_{0}} \times 100
$$

where $W t$ is the weight of the swollen sample at time $t$ and $W_{0}$ the weight of the corresponding hydrogels sample by lyophilization. After swelling, the hydrogels were dried in vacuum oven at $50^{\circ} \mathrm{C}$ until a constant weight and their gel fraction $(G)$ was calculated: ${ }^{23}$

$$
G \%=\frac{W_{1}}{W_{0}} \times 100
$$

The samples were weighted before $\left(W_{0}\right)$ and after being dried $\left(W_{l}\right)$.

\section{CONCLUSIONS}

In this work, PU/PVA hydrogels with improved surface properties were obtained as compared with those of the pure PVA hydrogel. The inclusion of different amount of PU into the PVA matrix made the PU/PVA hydrogels more porous reaching a diameter up to $21 \mu \mathrm{m}$ for $30 \%$ PU. As the Raman and ATR-FTIR analysis show, PU/PVA hydrogels provided the formations of different inter and intra molecular interactions. Also, the surface roughness and the swelling degree of the hydrogels increased suggesting that the incorporation of PU in different concentration can be a useful tool to improve the hydrogels properties.

Acknowledgements: The authors acknowledge the financial support of this research through the European Regional Development Fund, Project 'Partnerships for knowledge transfer in the field of polymer materials used in biomedical engineering' ID P_40_443, Contract no. 86/8.09.2016, MYSMIS 105689, cofinanced by the European Regional Development Fund by the Competitiveness Operational Programme 2014-2020, Axis 1 Research, Technological Development and Innovation in support of economic competitiveness and business development, Action 1.2.3 Knowledge Transfer Partnerships.

Also, the authors are very grateful to Dr. C. Ciobanu (Petru Poni Institute of Macromolecular Chemistry, Iaşi, Roumania) for polyurethane synthesis.

\section{REFERENCES}

1. J. Liu, S. Lin, L. Li and E. Liu, Int. J. Pharm., 2005, 298, 117-125.

2. M. Mandru, M. Bercea, L.M. Gradinaru, C. Ciobanu, M. Drobota, S. Vlad and R. Albulescu, Eur. Polym. J., 2019, 118, 137-145.

3. Y. Yuan and M. S. Shoichet, Macromolecules, 2000, 33, 4926-4931.

4. E. Calo and V. V. Khutoryanskiy, Eur. Polym. J., 2015, $65,252-267$.

5. L. M. Gradinaru, C. Ciobanu, S. Vlad, M. Bercea and M. Popa, Ind. Eng. Chem. Res., 2012, 51, 12344-12354.

6. M. Ding, J. Li, H. Tan and Q. Fu, Soft. Matter, 2012, 8, 5414-5428.

7. L. M. Gradinaru, C. Ciobanu, S. Vlad and M. Bercea, Rev. Roum. Chim., 2016, 61, 411-417.

8. A. Feula, A. Pethybridge, I. Giannakopoulos, X. Tang, A. Chippindale, C. R. Siviour, C. Paul Buckley, I. W. Hamley and W. Hayes, Macromolecules, 2015, 48, 6132-6141.

9. C. Wang, Y. Zheng, K. Qiao, Y. Xie and X. Zhou, RSC Adv., 2015, 5, 73882-73891.

10. M. Bercea, S. Morariu and D. Rusu, Soft Matter, 2013, 9, 1244-1253.

11. S. Patachia and C. B. Florea, Rev. Roum. Chim., 2007, $52,1145-1149$.

12. S. Morariu, M. Bercea, M. Teodorescu and M. Avadanei, Eur.Polym. J., 2016, 84, 313-325.

13. M. Bercea, G. Biliuta, M. Avadanei, R. I. Baron, M. Butnaru and S. Coseri, Carbohydr. Polym., 2019, 206, 210-219.

14. M. Mandru, C. Ciobanu, S. Vlad, M. Butnaru, L. Lebrun and M. Popa, Cent. Eur. J. Chem., 2013, 11, 542-553.

15. L. M. Gradinaru, C. Ciobanu, S. Vlad, M. Bercea and M. Popa, Cent. Eur. J. Chem., 2012, 10, 1859-1866.

16. M. M. Coleman, K. H. Lee, D. J. Skrovanek and P. C. Painter, Macromolecules, 1986, 19, 2149-2157.

17. M. M. Ghobashy and Z. I. Abdeen, J. Polym., 2016, 9, 9802514.

18. S. Parnell, K. Min and M. Cakmak, Polymer, 2003, 44, 5137-5144.

19. E. Tamahkar and B. Özkahraman, Hittite J. Sci. Eng., 2015, 2, 165-171.

20. S. R. Panda and S. De, RSC Adv, 2015, 5, 23599-23612.

21. M. Bercea, L. M. Gradinaru, M. Mandru, C. Ciobanu and D. L. Tigau, J. Mol. Liq., 2019, 274, 562-567.

22. M. Bercea, S. Morariu and M. Teodorescu, J. Polym. Res., 2016, 23, 1-9.

23. N. K. Hota, N. Karna., D. K. Tripathy, K. A. Dubey and B. P. Sahooa, Plast. Rubber Compos., 2019, 48, 248-255. 
